\title{
Diagnostics of the effect of prior cold deformation and aging time on intergranular corrosion resistance in case of austenitic stainless steel
}

\author{
Zdzisław Ławrynowicz ${ }^{1,1 *}$ \\ ${ }^{1}$ University of Science and Technology UTP, Mechanical Engineering Faculty, Department of \\ Materials Science and Engineering, Av. Kaliskiego 7, 85-796 Bydgoszcz, Poland
}

\begin{abstract}
Intergranular corrosion of commercial stainless steel type X6CrNiTi18-10 (1.4541, AISI 321) is frequently observed in several process environments. These localized attacks are normally attributed to the carbide precipitation and concomitant depletion of chromium near grain boundary due to steel exposure to sensitization temperature. Such undesirable microchemistry is expected to be changed further if the material undergoes deformation prior to sensitization. Present paper deals with the influence of a wide range of cold rolling $(5,10,15$ and maximum $40 \%$ cold deformation) and the sensitization time (aging at $700^{\circ} \mathrm{C}$ for $0.12,0.5,1,4$, 16 and 32 hours) on intergranular corrosion (IGC). The assessment of the degree of intergranular corrosion was based on the measurement of mass loss and observation of corroded surfaces on optical microscope. The consequences of deformation on IGC have been investigated by using EN ISO 3651-1methods (Huey test). Cold deformation before sensitization reduces the intensity of intergranular corrosion of this steel. The deformed structure created during the cold work process, numerous slip planes and the twins boundaries are just like the grain boundaries and the places where the chromium carbides preferentially precipitates.
\end{abstract}

\section{Introduction}

The stainless alloy X6CrNiTi18-10 (1.4541, AISI 321) is a general purpose austenitic stainless steel with a face centred cubic structure. It is essentially non-magnetic in the annealed condition, and can only be hardened by cold working. Titanium is added to suppress grain boundary chromium carbide precipitation, and to reduce susceptibility to intergranular corrosion, through the formation of very stable titanium carbide[1-3].

It knows that the most important corrosion form in case of austenitic steels is the intergranular corrosion. The well-known susceptibility of austenitic stainless steels to intergranular corrosion after heat-treatment in the temperature range of $500^{\circ}-800^{\circ} \mathrm{C}$ (sensitization) has long been attributed to depletion of $\mathrm{Cr}$ from regions of the alloy matrix adjacent to grain boundaries in which $\mathrm{Cr}_{23} \mathrm{C}_{6}$ had precipitated. Those regions of the steel in which the local $\mathrm{Cr}$ composition falls below about $12 \%$ have a diminished ability to form a passive film and hence corrode preferentially [4] (Fig. 1).

Stainless steels are common material of construction as these offer a wide range of corrosion resistance along with good fabrication and mechanical properties to many industrial environments. At the same time, these alloys are prone to microstructural changes along with changes in chemistry when exposed to sensitization temperatures possibly due to faulty heat treatment or welding operation. This causes frequent catastrophic failure of engineering components.

\footnotetext{
*Corresponding author: lawry@utp.edu.pl
} 


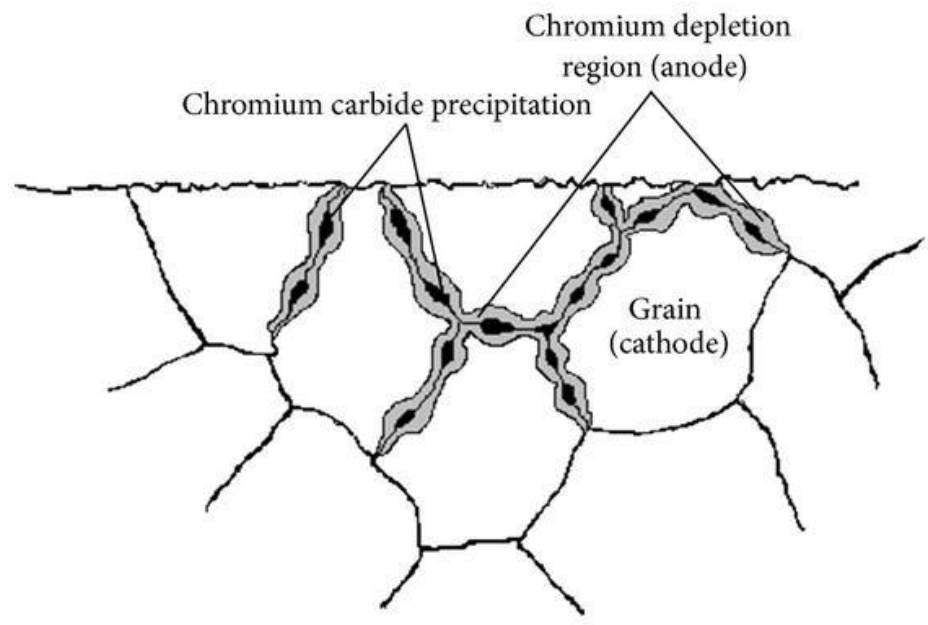

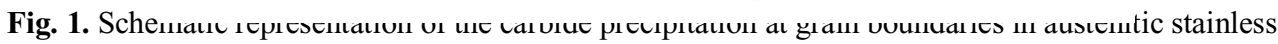
steel [4].

Before shaping the component into a desired geometry, steels often undergoes a thermomechanical processing during which materials change certain properties. Cold deformations are assumed to alter the properties of steels through increasing dislocation density which apart from its effect on mechanical properties, may help in accelerating the diffusion mechanism, phase transformation, lowering the activation energy for faster nucleation [2]. There have been contradictory remarks in the literature about the net influence of deformation on the sensitization kinetics of stainless steels. It was first studied by Bain and Tedmon [1, 2] who reported the lower corrosion of strained material compared to that of annealed. On the other hand Briant [3] observed higher resistance of the unstrained material. One reason of such conflicting results could be the consideration of low level of deformations only. Consequently, the need was felt to investigate the sensitization and intergranular corrosion behavior of austenitic stainless steel with wide range of deformation in order to understand the mechanism.

The present paper reports the results of various deformation levels on IGC and the attempt has been made to establish the correlation of corrosion rates with sensitization time and microstructure.

\section{Material}

The material that was investigated was the commercially available X6CrNiTi18-10 (1.4541, AISI 321) stainless steel. The chemical composition of the investigated material, which was determined by optical emission spectroscopy, is shown in Table 1. The samples provided were in a supersaturated state.

Table 1. Chemical composition of the X6CrNiTi18-10 steel used in this study. All concentrations are given in wt. $\%$.

\begin{tabular}{|c|c|c|c|c|c|c|c|}
\hline$\% \mathrm{C}$ & $\% \mathrm{Cr}$ & $\% \mathrm{Ni}$ & $\% \mathrm{Mn}$ & $\% \mathrm{P}$ & $\% \mathrm{Si}$ & $\% \mathrm{~S}$ & $\% \mathrm{Ti}$ \\
\hline 0.12 & 17.9 & 9.6 & 1.50 & 0.014 & 0.016 & 0.016 & 0.58 \\
\hline
\end{tabular}

The starting material was in the form of steel strips, thickness $g=3 \mathrm{~mm}$ and width $\mathrm{b}=100 \mathrm{~mm}$. These strips were then cold rolled with various degrees: 5, 10, 15 and maximum $40 \%$. Samples of size: $100 \times 20 \times 3 \mathrm{~mm}$ were cut from the deformed strips and 6 batches of samples were prepared, each batch containing: a sample without deformation, and cold worked samples of 5,10, 15 and $40 \%$, which were subjected to a sensitizing anealing at $700^{\circ} \mathrm{C}$ during : 5 minutes, 30 minutes, $1 \mathrm{~h}, 4 \mathrm{~h}, 16 \mathrm{~h}$ and $32 \mathrm{~h}$. Sensitization is a terminology used to describe 
the precipitation of carbides at grain boundaries of alloys during high-temperature exposure. The essence of sensitization is that the rate of attack of austenitic stainless steels under intergranular attack conditions is extremely sensitive to the carbides precipitated in the 500 to $800^{\circ} \mathrm{C}$ temperature range.

After the heat treatment sensitizing to intergranular corrosion, the samples were cooled in air. Two dimensions of samples were prepared to assess the intensity of intergranular corrosion:

a) $20 \times 20 \times 3 \mathrm{~mm}$ samples were used for the weight loss test by boiling in $\mathrm{HNO}_{3}$ (Huey test), b) metallographic samples were made on $10 \times 20 \times 3 \mathrm{~mm}$ samples and after boiling in the Huey reagent, observations were made on optical and scanning microscopes,

Huey test was aimed at determining the intensity of intergranular corrosion by measuring the loss of mass during boiling in $\mathrm{HNO}_{3}$. Boiling consisted of 3 periods of 40 hours each with each exchange of acid after boiling. Before weighing, the samples were thoroughly rinsed in water and the corrosion products were removed with a soft rubber. After drying, the samples were weighed with an accuracy of $0.0001 \mathrm{~g}$.

\section{Experimental procedures}

Optical microscopy was used to examine etched structures. Microscopic images were recorded using the inverted metallographic microscope Nikon MA100 equipped with the ERC5s digital camera and the ZEN 2011 archiving program.

The Huey test (EN-ISO 3651-1. Determination of resistance to intergranular corrosion of stainless steels-Part 1: Austenitic and ferritic-austenitic (duplex) stainless steelsCorrosiontest in nitric acid medium by measurement of loss in mass ) [5] was used, consisting of boiling in concentrated $\mathrm{HNO}_{3}$ (nitric acid) at $95^{\circ} \mathrm{C}$ for three periods of time, each 40 hours. This test can generate intergranular corrosion in the austenitic steel. Before immersing the test specimens in nitric acid, they were well degreased with acetone solution and weighed to the fourth point of decimal (grams). After each test period the specimens were cleaned and weighed. The corrosion rates were obtained by using the formula (1) and are reported in $(\mathrm{g} \times$ $\left.\mathrm{m}^{-2} \times \mathrm{h}^{-1}\right)$.

\section{Results of Huey test}

Corrosion losses of sample mass after each boiling cycle are presented in Table 2.

Table 2. Mass losses of samples after boiling in $\mathrm{HNO}_{3}$ during 40, 80 and 120 hours

\begin{tabular}{|l|l|c|c|c||c|c|c|}
\hline Lp. & $\begin{array}{l}\text { Time of } \\
\text { sensitization }\end{array}$ & \multicolumn{3}{|c||}{$\begin{array}{l}\text { After solution heat treatment, } \\
\text { State supersaturated }\end{array}$} & \multicolumn{3}{c|}{ Cold work 5\% } \\
\hline & \multicolumn{4}{|c|}{$\begin{array}{l}\text { Weight loss of the sample in } \\
\text { grams after boiling in } \mathrm{HNO}_{3} \\
\text { at the time: }\end{array}$} & $\begin{array}{l}\text { Weight loss of the sample in } \\
\text { grams after boiling in } \mathrm{HNO}_{3} \\
\text { at the time: }\end{array}$ \\
\hline & & $40 \mathrm{~h}$ & $80 \mathrm{~h}$ & $120 \mathrm{~h}$ & $40 \mathrm{~h}$ & $80 \mathrm{~h}$ & $120 \mathrm{~h}$ \\
\hline & & $G_{1}$ & $G_{2}$ & $G_{3}$ & $G_{1}$ & $G_{2}$ & $G_{3}$ \\
\hline 1. & $5 \mathrm{~min}$. & 0.0101 & 0.0212 & 0.0473 & 0.0108 & 0.0255 & 0.0533 \\
\hline 2. & $30 \mathrm{~min}$. & 0.0185 & 0.1069 & 0.2671 & 0.0109 & 0.0273 & 0.0783 \\
\hline 3. & $1 \mathrm{~h}$ & 0.0216 & 0.1506 & 0.3005 & 0.0138 & 0.0303 & 0.0770 \\
\hline 4. & $4 \mathrm{~h}$ & 0.0219 & 0.0795 & 0.2053 & 0.0128 & 0.0307 & 0.0510 \\
\hline 5. & $16 \mathrm{~h}$ & 0.0152 & 0.0305 & 0.0406 & 0.0123 & 0.0239 & 0.0443 \\
\hline 6. & $32 \mathrm{~h}$ & 0.0170 & 0.0433 & 0.0473 & 0.0129 & 0.0248 & 0.0520 \\
\hline
\end{tabular}

Continued Table 2. 


\begin{tabular}{|c|c|c|c|c|c|c|c|c|c|c|}
\hline \multirow[t]{3}{*}{ No. } & \multirow{3}{*}{$\begin{array}{l}\text { Time of } \\
\text { sensiti- } \\
\text { zation }\end{array}$} & \multicolumn{3}{|c|}{ Cold work $10 \%$} & \multicolumn{3}{|c|}{ Cold work $15 \%$} & \multicolumn{3}{|c|}{ Cold work $40 \%$} \\
\hline & & \multicolumn{3}{|c|}{$\begin{array}{l}\text { Weight loss of the sample in } \\
\text { grams after boiling in } \mathrm{HNO}_{3} \\
\text { at the time: }\end{array}$} & \multicolumn{3}{|c|}{$\begin{array}{l}\text { Weight loss of the sample in } \\
\text { grams after boiling in } \mathrm{HNO}_{3} \\
\text { at the time: }\end{array}$} & \multicolumn{3}{|c|}{$\begin{array}{l}\text { Weight loss of the sample in } \\
\text { grams after boiling in } \mathrm{HNO}_{3} \\
\text { at the time: }\end{array}$} \\
\hline & & $40 \mathrm{~h}$ & $80 \mathrm{~h}$ & $120 \mathrm{~h}$ & $40 \mathrm{~h}$ & $80 \mathrm{~h}$ & $120 \mathrm{~h}$ & $40 \mathrm{~h}$ & $80 \mathrm{~h}$ & $120 \mathrm{~h}$ \\
\hline & & $G_{l}$ & $G_{2}$ & $G_{3}$ & $G_{l}$ & $G_{2}$ & $G_{3}$ & $G_{l}$ & $G_{2}$ & $G_{3}$ \\
\hline 1. & 5 min. & 0.0103 & 0.0205 & 0.0395 & 0.0103 & 0.0167 & 0.0388 & 0.0103 & 0.0198 & 0.0306 \\
\hline 2. & $30 \mathrm{~min}$. & 0.0115 & 0.0194 & 0.0310 & 0.0111 & 0.0152 & 0.0372 & 0.0020 & 0.0102 & 0.0341 \\
\hline 3. & $1 \mathrm{~h}$ & 0.0101 & 0.0193 & 0.0332 & 0.0078 & 0.0158 & 0.0364 & 0.0099 & 0.0175 & 0.0239 \\
\hline 4. & $4 \mathrm{~h}$ & 0.0114 & 0.0183 & 0.0378 & 0.0096 & 0.0147 & 0.0240 & 0.0068 & 0.0153 & 0.0222 \\
\hline 5. & $16 \mathrm{~h}$ & 0.0125 & 0.0226 & 0.0359 & 0.0116 & 0.0210 & 0.0458 & 0.0123 & 0.0228 & 0.0338 \\
\hline 6. & $32 \mathrm{~h}$ & 0.0132 & 0.0203 & 0.0427 & 0.0171 & 0.0249 & 0.0403 & 0.0126 & 0.0246 & 0.0257 \\
\hline
\end{tabular}

Assessment of the intensity of intergranular corrosion after boiling test in $\mathrm{HNO}_{3}$ was based on determining the average corrosion rate $V_{c o r}$ according to PN-EN ISO 3651-1 [5]:

where:

$$
V_{\text {cor }}=\frac{10000 \mathrm{~m}}{S t}
$$

$t$ - time of cooking the solution in hours,

$S$ - surface area of the test sample, in square centimeters

$m$ - the average loss in mass of the sample during the test in grams

$m=G_{1}-G_{2}$

where:

$G_{l}$ - weight of the sample before boiling (g),

$G_{2}$ - sample weight after boiling (g).

The corrosion rate after each cooking cycle and the average corrosion speed are shown in Table 3.

Table 3. Corrosion rate $V_{1}, V_{2}$ and $V_{3}$ after the boiling cycle during 40,80 and 120 hours and the average arithmetic corrosion rate $V_{a v},\left(\mathrm{~g} \times \mathrm{m}^{-2} \times \mathrm{h}^{-1}\right)$

\begin{tabular}{|c|c|c|c|c|c|c|c|c|c|}
\hline \multirow[t]{3}{*}{ No. } & \multirow{3}{*}{$\begin{array}{l}\text { Time of } \\
\text { sensiti- } \\
\text { zation }\end{array}$} & \multicolumn{4}{|c|}{$\begin{array}{l}\text { After solution heat treatment, } \\
\text { State supersaturated }\end{array}$} & \multicolumn{4}{|c|}{ Cold work 5\% } \\
\hline & & \multicolumn{4}{|c|}{$\begin{array}{l}\text { Corrosion rate, } \times 10 \\
V_{a v},\left(\mathrm{~g} \times \mathrm{m}^{-2} \times \mathrm{h}^{-1}\right)\end{array}$} & \multicolumn{4}{|c|}{ 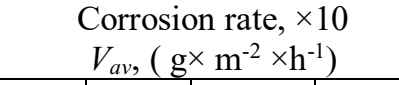 } \\
\hline & & $V_{l}$ & $V_{2}$ & $V_{3}$ & $V_{a v}$ & $V_{l}$ & $V_{2}$ & $V_{3}$ & $V_{a v}$ \\
\hline 1. & $5 \mathrm{~min}$. & 2.4 & 5.3 & 11.6 & 6.4 & 2.6 & 6.3 & 13.0 & 7.3 \\
\hline 2. & $30 \mathrm{~min}$. & 4.4 & 25.7 & 64.3 & 31.5 & 2.7 & 6.7 & 19.2 & 9.5 \\
\hline 3. & $1 \mathrm{~h}$ & 5.3 & 36.8 & 73.6 & 38.6 & 3.4 & 7.2 & 19.1 & 9.9 \\
\hline 4. & $4 \mathrm{~h}$ & 5.1 & 18.7 & 48.3 & 24.0 & 3.0 & 7.2 & 12.0 & 7.3 \\
\hline 5. & $16 \mathrm{~h}$ & 3.6 & 7.3 & 9.7 & 6.5 & 2.8 & 5.8 & 10.8 & 6.5 \\
\hline 6. & $32 \mathrm{~h}$ & 4.1 & 10.4 & 11.4 & 8.6 & 3.1 & 5.9 & 12.5 & 7.2 \\
\hline
\end{tabular}

continued Table 3. 


\begin{tabular}{|c|c|c|c|c|c|c|c|c|c|c|c|c|c|}
\hline \multirow[t]{3}{*}{ No. } & \multirow{3}{*}{$\begin{array}{l}\text { Time of } \\
\text { sensiti- } \\
\text { zation }\end{array}$} & \multicolumn{4}{|c|}{ Cold work $10 \%$} & \multicolumn{4}{|c|}{ Cold work $15 \%$} & \multicolumn{4}{|c|}{ Cold work $40 \%$} \\
\hline & & \multicolumn{4}{|c|}{$\begin{array}{c}\text { Corrosion rate, } \times 10 \\
V_{a v},\left(\mathrm{~g} \times \mathrm{m}^{-2} \times \mathrm{h}^{-1}\right)\end{array}$} & \multicolumn{4}{|c|}{$\begin{array}{c}\text { Corrosion rate, } \times 10 \\
V_{a v},\left(\mathrm{~g} \times \mathrm{m}^{-2} \times \mathrm{h}^{-1}\right)\end{array}$} & \multicolumn{4}{|c|}{$\begin{array}{c}\text { Corrosion rate, } \times 10 \\
V_{a v},\left(\mathrm{~g} \times \mathrm{m}^{-2} \times \mathrm{h}^{-1}\right)\end{array}$} \\
\hline & & $V_{1}$ & $V_{2}$ & $V_{3}$ & $V_{a v .}$ & $V_{1}$ & $V_{2}$ & $V_{3}$ & $V_{a v}$ & $V_{1}$ & $V_{2}$ & $V_{3}$ & $V_{a v}$ \\
\hline 1. & $5 \mathrm{~min}$. & 2.4 & 4.9 & 9.4 & 5.6 & 2.4 & 4.0 & 9.3 & 5.2 & 2.6 & 5.0 & 7.8 & 5.1 \\
\hline 2. & $30 \mathrm{~min}$. & 2.7 & 4.7 & 7.4 & 4.9 & & & & & 2.0 & 3.0 & 8.7 & 4.6 \\
\hline 3. & $1 \mathrm{~h}$ & 2.4 & 4.8 & 8.1 & 5.1 & 1.9 & 3.8 & 8.9 & 4.9 & 2.5 & 4.4 & 6.1 & 4.3 \\
\hline 4. & $4 \mathrm{~h}$ & 2.8 & 4.4 & 9.2 & 5.5 & 2.3 & 3.6 & 5.9 & 3.9 & 2.2 & 3.9 & 5.7 & 3.9 \\
\hline 5. & $16 \mathrm{~h}$ & 3.0 & 5.4 & 8.6 & 5.7 & 2.8 & 5.0 & 10.1 & 5.4 & 3.1 & 5.8 & 8.6 & 5.0 \\
\hline 6. & $32 \mathrm{~h}$ & 3.2 & 4.9 & 10.4 & 6.2 & 4.1 & 5.9 & 9.7 & 6.6 & 3.2 & 6.2 & 6.5 & 5.3 \\
\hline
\end{tabular}

The dependence of changes in the intensity of intergranular corrosion from the time of sensitization and degree of cold work are shown in Figure 2.

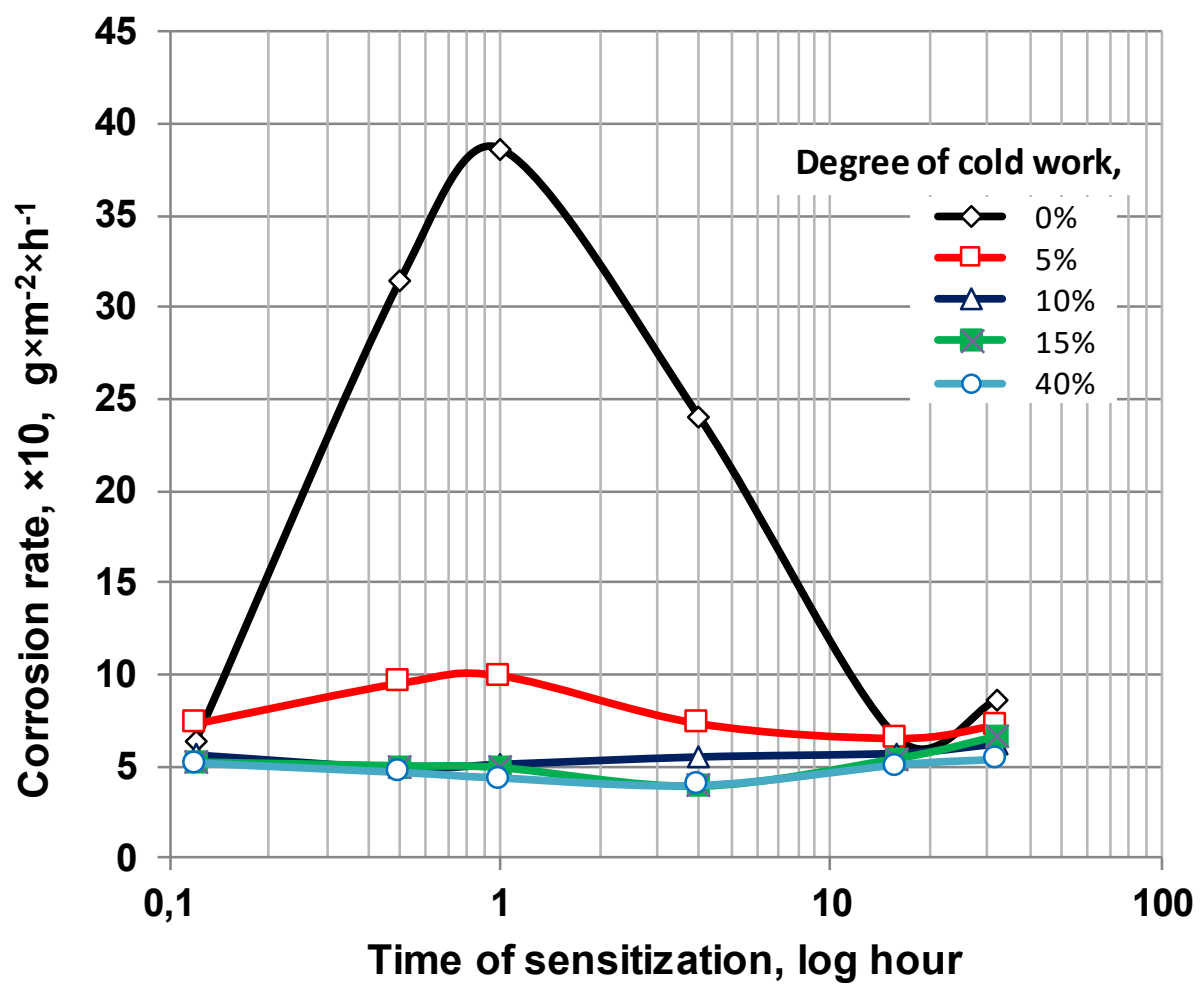

Fig. 2. Dependence of the intergranular corrosion rate in X6CrNiTi18-10 steel on time of sensitization for different degrees of cold work.

\section{Microstructure and analysis}

The microstructure of the investigated stainless steel sample (Fig. 3a), observed by an optical microscope, was austenitic. Metallographic investigation revealed austenitic polygonal grain features intersected with annealing twins and slips, produced by cold working (Fig. 3b). 


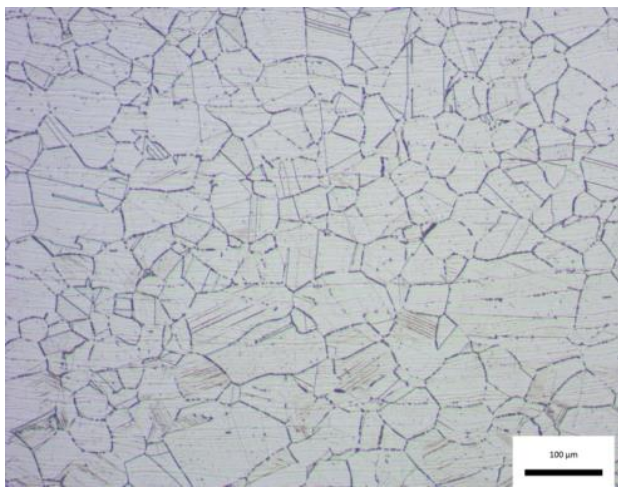

a)

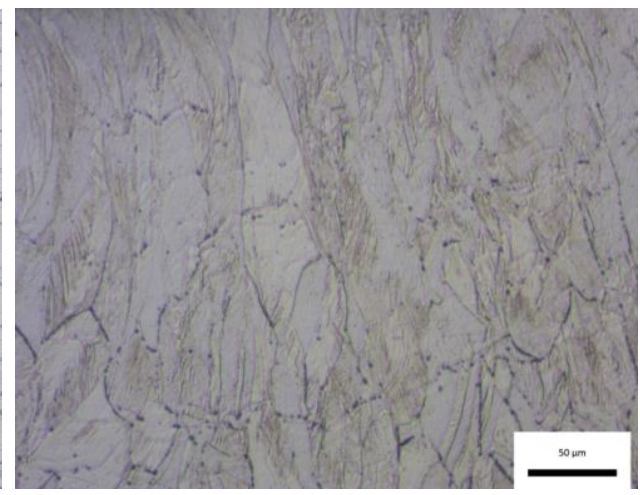

b)

Fig. 3. Microstructure of X6CrNiTi18-10 steel, a) supersaturated state, no deformation, b) cold work $40 \%$.

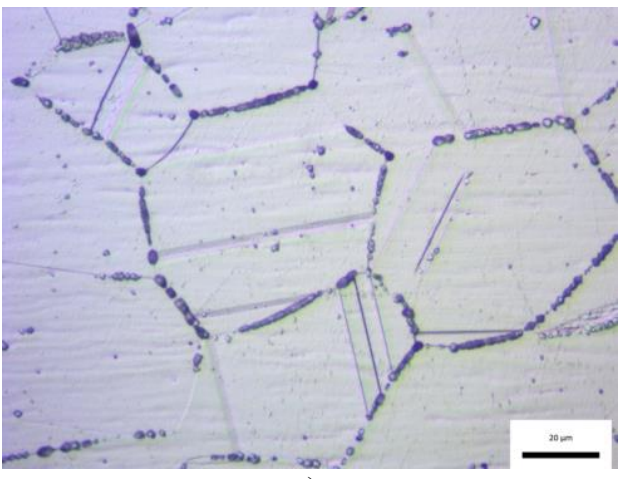

a)

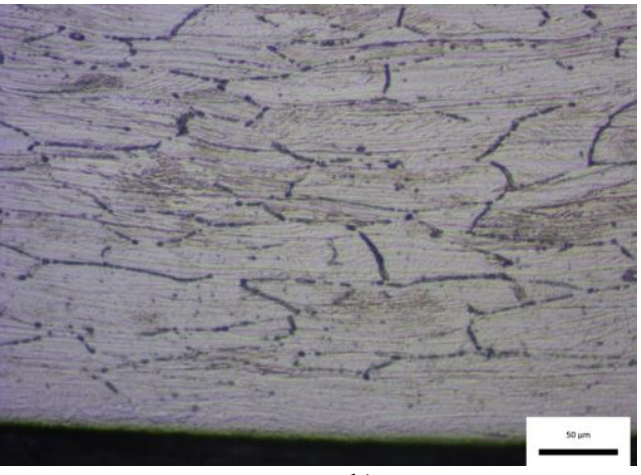

b)

Fig. 4. Microstructure of $\mathrm{X} 6 \mathrm{CrNiTi} 18-10$ steel after sentizitation at $700^{\circ} \mathrm{C} / 1 \mathrm{~h}$, a) cold work $0 \%$, b) cold work $40 \%$

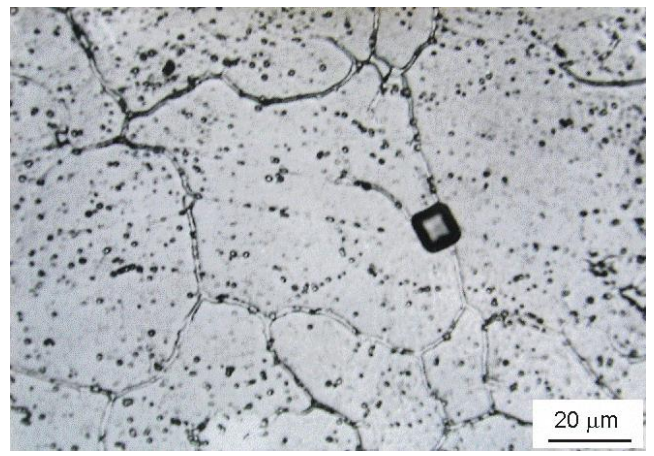

a)

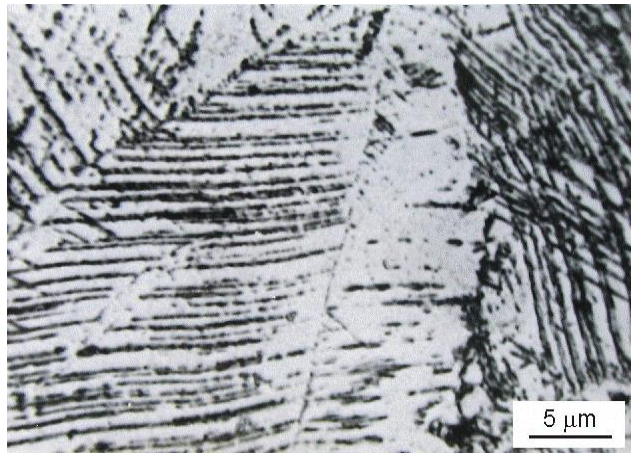

b)

Fig. 5. Microstructure of $\mathrm{X} 6 \mathrm{CrNiTi} 18-10$ steel after sentizitation at $700^{\circ} \mathrm{C}$, a) 32 hours, cold work $10 \%$, b) 16 hours, cold work $40 \%$.

An attempt to boil in $\mathrm{HNO}_{3}$ as well as microscopic observations showed that the deformation (starting from just 5\% small crushing forces) very clearly reduces the susceptibility of X6CrNiTi18-10 steel to intergranular corrosion (Fig. 2). This steel, in the supersaturated state, intensely corrodes intercrystalline, while the deformation of 5\%, especially $10 \%, 15 \%$ and maximum $40 \%$, significantly reduces the tendency of this steel to intercrystalline corrosion (Fig. 2). 
For X6CrNiTi18-10 steel in the supersaturated state, the most intense corrosion occurs after heating at $700^{\circ} \mathrm{C}$ from 30 minutes to 4 hours. After prolonged heating periods at a temperature of $700^{\circ} \mathrm{C}$, the intensity of corrosion decreases. This phenomenon may be a confirmation of the validity of the theory of depletion of chromium of grain boundaries, which explains the sensitization of austenitic steels to intergranular corrosion [6-8].

The Fig. 2 shows that as the heating time increases about 1 hour for steel in the supersaturated state, the intensity of corrosion decreases.

In this first stage of annealing (up to about 1 hour), due to the precipitation of the carbide phase at the boundaries of austenite grains, the process of depleting in chromium the border regions of the grain takes place, thus reducing their stability.

In the second stage, for longer boiling times, there is diffusion of chromium atoms from the internal grain regions towards the border zones, which were previously depleted in chromium. These zones, after the time required for the diffusion of chromium atoms to the grain boundaries, are again enriched with chromium, and when its content reaches $12.5 \%$, they regain stability and thus become resistant to the corrosive effects of the environment. Cold work of X6CrNiTi18-10 steel very clearly improves its resistance to intergranular corrosion. With increasing deformationy, corrosion resistance of this steel is also gradually increasing. The obtained results are consistent with the general view that cold work before sensitization, reduces the intensity of intergranular corrosion [7-9]. This is due to the deformation of the structure (twins, slip bands, stacking errors, grain refinement) (Fig. 4, 5). All these places are similar to the grain boundaries, in places of the privileged precipitation of carbide phases, as a result of which the concentration of the separated phases on the grain boundaries is smaller, and thus the corrosion rate decreases. Also the composition of steel has a large influence on the tendency of steel to intercrystalline corrosion in the case of the addition of titanium [10-11]. Titanium reduces the formation rate of $\mathrm{M}_{23} \mathrm{C}_{6}$ carbides to a very large extent, because a significant part of the carbon is bound in titanium carbonitride $\operatorname{Ti}(\mathrm{CN})$.

\section{Conclusions}

The effect of prior cold deformation and sensitization time on intergranular corrosion resistance in X6CrNiTi18-10 austenitic stainless steel were investigated. The following conclusions were drawn:

1. Intergranular corrosion of undeformed specimens increases with sensitization time of exposure up tp 1 hour. Sensitization of the X6CrNiTi18-10 steels accelerated the precipitation of the carbides which were also detected on the grain boundaries and in the austenitic matrix in the case of cold working samples.

2. High deformations reduces rate of intergranular corrosion. After $40 \%$ cold working, even the sites inside the grain matrix have high energy, and carbides can nucleate there easily.

\section{References}

1. E. C. Bain, R.H. Aborn, and J.J.B. Rutherford, Trans Amer. Soc. Steel Treating, 21, 481-509 (1993)

2. C.S. Tedmon, Jr. D.A. Vermilye and D.E. Broecker, Corrosion, 27, 104-106 (1971)

3. C.L. Briant and A.M. Ritter, Metall Trans A, 11A, 2009-2017 (1980)

4. F. Haraszti and T. Kovacs, IOP Conf. Series: Materials Science and Engineering, 175 (2017) 012048 ((http://iopscience.iop.org/1757-899X/175/1/012048))

5. PN-EN ISO 3651-1:2004. Determination of resistance to intergranular corrosion of stainless steels-Part 1: Austenitic and ferritic-austenitic (duplex) stainless steelsCorrosion test in nitric acid medium by measurement of loss in mass (Huey test)

6. A.H. Advani, L.E. Murr, D.G. Atteridge, and R. Chelakara, Metall Trans A, 22A, p.2917 (1991) 
7. G.E. Deiter, Mechanical Metallurgy, Mc-Graw-Hill, 1988, p.139

8. H. Zhao, Z. Zhang, H. Zhang, J. Hu, J. Li, Journal of Alloys and Compounds, 672, 147-154 (2016)

9. H. Luo, H. Sub, G. Yinga, C. Dongc, X. Li, Applied Surface Science 425, 628-638 (2017)

10. L. Zhang, J. A. Szpunar, R. Basu, J. Dong, M. Zhang, Journal of Alloys and Compounds, 616, 235-242 (2014)

11. M. Terada, M. Saiki, I. Costa, A. F. Padilha, Journal of Nuclear Materials, 358, 40-46 (2006) 